\title{
DESIGN, DEVELOPMENT AND TESTS OF A COMPACT THERMOFLUID SYSTEM ${ }^{1}$
}

\author{
Steve Q. Cai, Ya-Chi Chen and Avijit Bhunia \\ Teledyne Scientific \& Image Company \\ 1049 Camino Dos Rios, \\ Thousand Oaks, CA 91360 \\ Email: qcai@teledyne.com
}

${ }^{1}$ Distribution Statement: A (Sponsor, DARPA, required statement for releasing to public) 


\section{ABSTRACT}

To mitigate temperature overshoot and dissipate highly concentrated heat from high-power electronic components, it is important to develop an ultrathin vapor chamber/heat spreader to fit in a compact 3D electronic system. As a semiconductor material, silicon is highly thermal conductive, micromachinable and process-compatible with microelectronic manufactures. Thus, a silicon based vapor chamber (SVC) can be directly integrated with microelectronic devices to achieve hot spot cooling, without introducing an additional thermal interface. In this article, development of SVC is initiated from analyses of structural safety, followed by numerical simulations of the liquid and vapor flows. Advanced multiscale wick structures are implemented to balance the heat and mass transports of high heat flux under a gravitational force. On these bases, SVC with structural reinforcement of a $13 \times 8$ pillar array is developed through a triple bonding approach. The successful development of the SVCs results in the emergence of a large scale $(50 \mathrm{~mm} \times 70 \mathrm{~mm})$ and ultrathin $(1 \mathrm{~mm}$ thick) phase change heat transfer device, with the effective density less than $1.5 \times 10^{3} \mathrm{~kg} / \mathrm{m}^{3}$. Using water as the operating fluid, high effective thermal conductivity over $10,000 \mathrm{~W} / \mathrm{m} . \mathrm{K}$ is experimentally demonstrated in both $1 \mathrm{D}$ and $2 \mathrm{D}$ heat transfer modes.

Keywords: heat pipe, vapor chamber, wick structure, phase change 


\section{NOMENCLATURE}

$\begin{array}{ll}A & \text { area, } \mathrm{m}^{2} \\ a & \text { acceleration, } \mathrm{m} / \mathrm{s}^{2} \\ k & \text { length, } \mathrm{m} \\ P & \text { thermal conductivity, W/m.K } \\ Q & \text { pressure, } \mathrm{Pa} \\ r & \text { input heat, } \mathrm{W} \\ T & \text { effective pore radius, } \mathrm{m} \\ t & \text { Temperature, }{ }^{\circ} \mathrm{C}\end{array}$

\section{Greek symbols}

$\sigma$

surface tension, $\mathrm{N} / \mathrm{m}$

$\rho \quad$ density, $\mathrm{kg} / \mathrm{m}^{3}$

$\phi \quad$ inclined angle, ${ }^{\circ}$

$\Delta \quad$ difference

\section{Subscripts}

$c$

cross section

cap capillary

eff effective

$l \quad$ liquid

$v \quad$ vapor 


\section{INTRODUCTION}

A heat pipe is a liquid-vapor phase change heat transfer systems ${ }^{[1]}$. Over the past thirty years, this technology has been extensively applied to electronic thermal management because of their highly effective phase change heat transfer, passive operation mechanism and low manufacturing cost. In the heat pipe system, operating fluid evaporates when heat is dissipated from an electronic device into the evaporator section. Under the saturation pressure difference, vapor flows to the condenser region, and condenses. By the capillary force of a porous structure (or called wick structure), the condensate is pumped back to the evaporator section. In this dynamic circulation, heat and mass transports are limited by a few limitations, such as capillary and sonic limits. These limitations provide design guidelines for developing heat pipes. In various heat pipe systems, a 2D heat pipe system is also called a heat spreader, or a vapor chamber. The vapor chamber spreads the highly concentrated heat from electronic components and dissipates it over a much larger substrate/heat sink surface area.

The traditional heat pipes are made of highly conductive metals, such as copper, and are able to demonstrate very high effective thermal conductivity $\geq 20 \mathrm{~kW} / \mathrm{m} . \mathrm{K}$. However, recent advances of high-power 3D microelectronics bring new demands and challenges to apply this technology. In these applications, it is more important that the heat transfer device can be directly bonded with electronic systems without the introduction of thermal interface or package layers. Such the heat pipe heat transfer device must also be compact enough to fit in a limited electronic system space. The device packaging material must have high thermal conductivity, be micro machinable, be compatible with the microelectronic manufacturing process, and have similar thermomechanical properties (e. g. thermal expansion coefficient) to most electronic semiconductors. 
As a major material in IC manufacturing, silicon has high thermal conductivity and can be precisely micro-fabricated using MEMS (microelectromechanical systems) processes. It also has a thermal expansion coefficient compatible with most semiconductors. These characteristics make it an ideal material for developing micro/mini vapor chambers for high-power electronic cooling. In history, the development of the silicon-based heat pipe was first explored by Peterson et al. ${ }^{[2]}$. More experimental and analytical efforts were reported by Ivanova et al. ${ }^{[3][5]}$, Gillot et al. ${ }^{[4]}$, M. Hamdan ${ }^{[6]}$, M. L. Berre ${ }^{[7]}$, S. Lips ${ }^{[8]}$, U. Vadakkan ${ }^{[9]}$ and Q. Cai ${ }^{[10]}$ in recent years. Most results demonstrated enhanced heat transfer performance, improved compatibility between operating fluid and packaging materials, optimized fabrication processes, and reduced junction temperature. Nevertheless, development progress has been limited to small scale prototyping in the laboratory. Various issues, in the aspects of structural reinforcement, high-yielded MEMS processes, highly viscous vapor and liquid flows in ultrathin structures, and vacuum \& charging approach compatible with manufacturing processes, need to be addressed before this technology can be applied to the electronic industry.

Development of an ultrathin SVC heat transfer system confronts technical challenges from various aspects, including wafer processing capability of a cleanroom (e.g. the maximum wafer size), application constrains (e.g. the surface area ratio between the electronic device and the SVC), as well as the heat and mass transfer requirements in the wick structure and vapor channel (e.g. high liquid pressure drop in the thin wick structure). In this article, the development is based on 4-inch wafer MEMS fabrication technology. The goal is to develop $50 \mathrm{~mm} \times 70 \mathrm{~mm}$ large and $1 \mathrm{~mm}$ thick SVCs, capable of high heat flux heat transfer on a $5 \mathrm{~mm} \times 8 \mathrm{~mm}$ heating area. The development effort started from structural analysis of the ultrathin SVC. After ensuring the structural safety, numerical analysis was performed to quantify the heat and mass transport resistance in the vapor chamber. With successful development of the ultrathin and large scale 
SVC, experimental characterization was conducted to evaluate the hermetic seal and the effective thermal conductivity.

\section{CONFIGURATION OF THE 1MM THICK SVC}

The SVC design is an iterated process, based on the system requirements in structural safety, heat and mass transfers, and the maximum heat transfer capability, etc., to refine the design parameters. This process is from a conceptual SVC configuration. On this basis, various evaluation models are applied to verify its theoretical rationality and engineering feasibility. Reconfigurations may be needed if it is failed to meet one or more design criterions. The SVC parameters are finalized after all application requirements are satisfied through the iterated process.

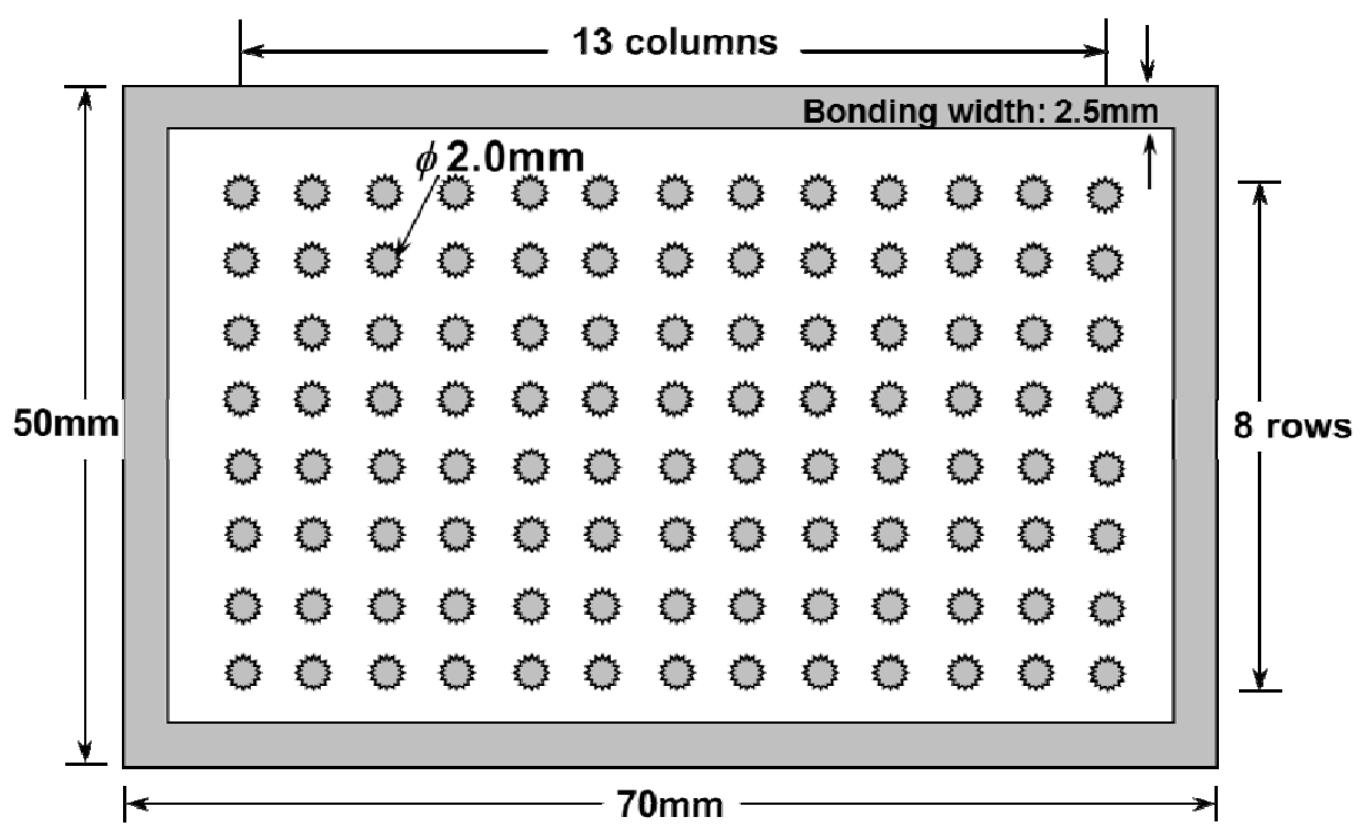

Fig. 1 Top view of the cross-section of the SVC configuration

The top view of a cross-section of the SVC design configuration is shown in Fig. 1. The SVC contains $8 \times 13$ supporting pillars, $2.0 \mathrm{~mm}$ in diameter. The reinforcement pillars increase the 
structural strength to withstand the pressure difference between the internal and external environments. To mitigate the stress concentration, all the gaps between silicon pillars, as well as the gaps between the silicon pillar and packaging wall, are maintained equal at $2.7 \mathrm{~mm}$. Sidewalls of each silicon pillar and SVC are etched to contain perpendicular micro grooves that bridge liquid phase flow between the top wick layer and the bottom wick layer, as shown in Fig. 2. The arrows illustrate the liquid flow directions when the condensation occurs at the bottom surface of SVC.

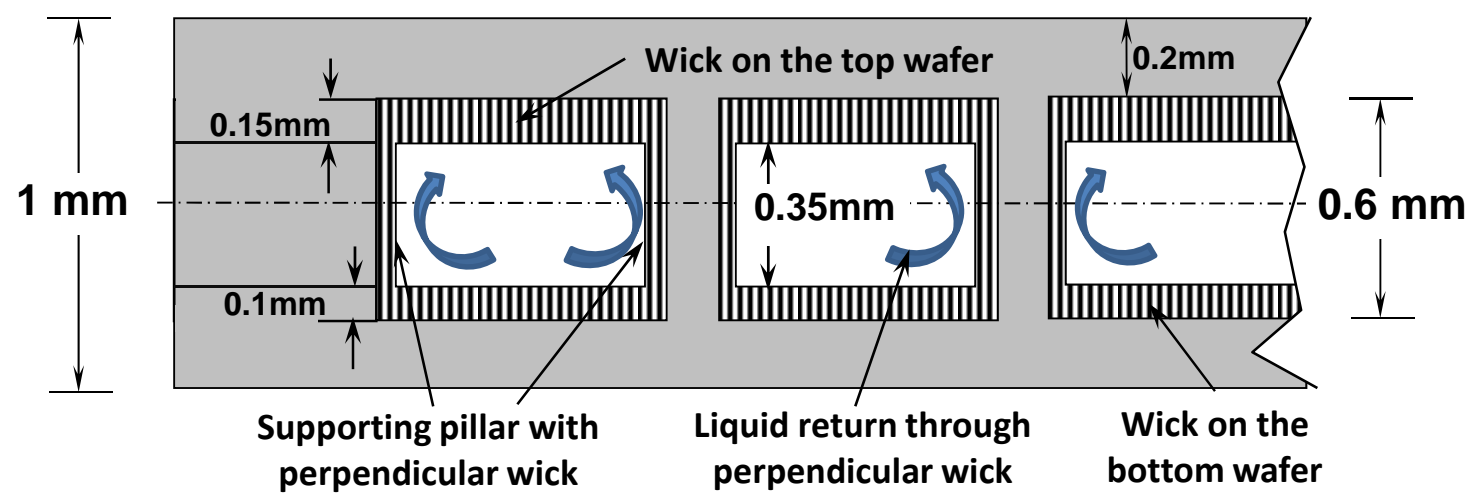

Fig. 2 Side view of the cross-section of the SVC configuration

The total SVC thickness of $1 \mathrm{~mm}$ is shared by the layers of package walls, wick structures and void cavity (shown in Fig. 2). Considering the flow speed is different in the wick structures between the upper evaporator and the bottom condenser, a thicker evaporator wick of $150 \mu \mathrm{m}$ on the top wafer is designed to enhance liquid supply capability. In contrast, thickness of the condenser wick is reduced to $100 \mu \mathrm{m}$. By reserving $350 \mu \mathrm{m}$ thick cavities for high-speed vapor flow, the thickness of both the top and bottom package walls is kept at $200 \mu \mathrm{m}$.

STRUCTURAL AND THERMOFLUID MODELING 


\section{STRUCTURAL ANALYSIS}

In an electronic thermal management system, SVC is located in the middle layer of the heat transfer structure. The SVC receives heat from the upstream microelectronic devices, and dissipates it to its downstream heat sink (e.g. a cold plate). Generally, the maximum operating temperature of the SVC is below $120^{\circ} \mathrm{C}$. If using water as the operating fluid and given a temperature safety margin of $5^{\circ} \mathrm{C}$, the maximum saturation pressure at $125^{\circ} \mathrm{C}$ would reach $2.1 \times 10^{5} \mathrm{~Pa}$. Under this pressure load, structural safety plays a critical role on development of the ultrathin and hollow SVC devices.

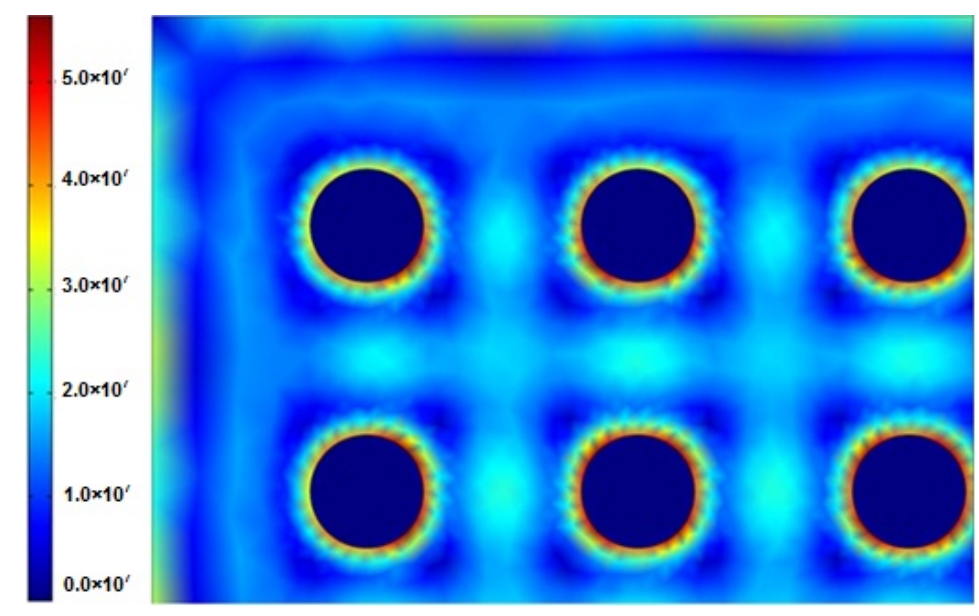

Fig. 3 Stress contour near the SVC corner, subjected to $1 \mathrm{MPa}$ pressure load. The maximum stress of 56MPa is shown around supporting pillars.

The structural simulation was carried out with the finite element method using plate elements, subjected to a uniform pressure of 1.0MPa. This pressure load, about 5 times higher than maximum saturation pressure of the SVC, also reflects structural loads with moderate shocks and vibrations. Based on the SVC design with $8 \times 13$ supporting pillars, the simulated stress distribution is plotted in Fig. 3. The maximum Von Mises stress aggregates on the circumference of each pillar. Along the four edges of the vapor chamber, the mid-sections between two adjacent pillars carry higher stresses (yellow area shown on the upper and left edges 
of Fig. 3). In contrast, the four corner vertices are subject to the lowest stress under uniform pressure loading.

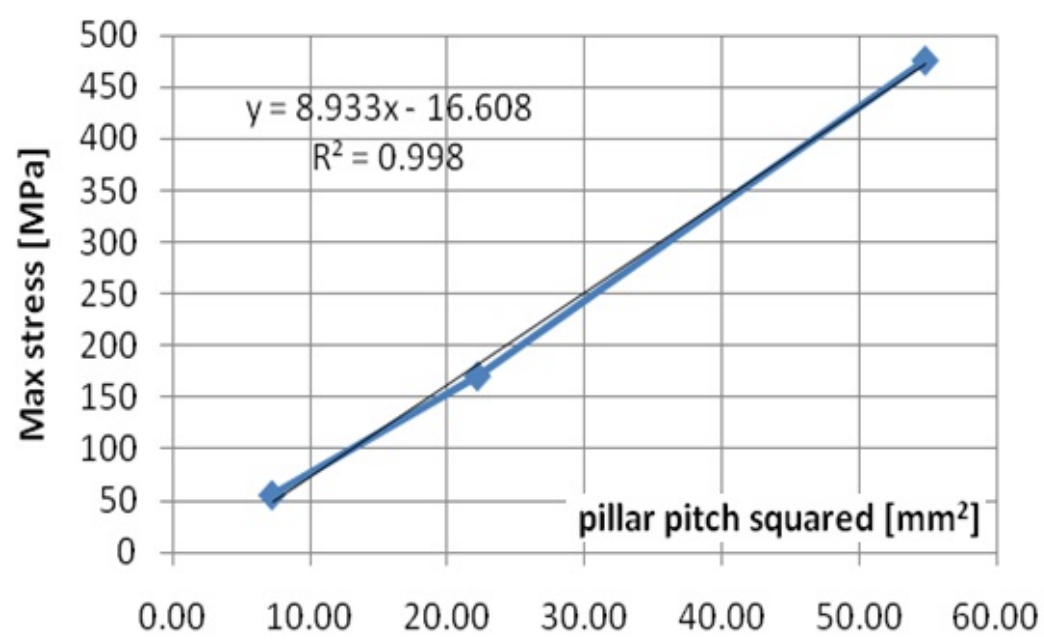

Fig. 4 The maximum stress is proportional to the squared of the pillar pitch.

The maximum silicon stress of 220MPa is defined on median fractural strength at $50 \%$ possibility level, given by Lindroos, et al. ${ }^{[11]}$. At compressive strength of 1.0MPa, the maximum stress is approximately 56MPa. The over-designed SVC has a safety factor close to $392 \%$. By varying the numbers of the supporting pillars, as shown in Fig. 4, structural simulation indicates that the maximum stress is proportional to the pillar pitch squared. If one pillar fails due to bonding failure, the maximum stress quickly rises. For SVC with supporting pillars array of $13 \times 8$ with the inner pitch of $2.7 \mathrm{~mm}$, failure of one supporting pillar doubles the effective innerpitch to $5.4 \mathrm{~mm}$. The maximum stress is raised to $243 \mathrm{MPa}$, equivalent to the maximum material strength. Considering that the given pressure load is 5 times higher than the designed standard, debond of a single isolated pillar would not risk to damage the SVC.

SIMULATIONS OF HEAT AND MASS TRANSFERS 
Heat and mass transfer simulation is based on a concentrated heat source of $5 \mathrm{~mm} \times 8 \mathrm{~mm}$, locating at the bottom-right of the SVC. The heat source size and location correspond to an electronic device, such as a GaN power amplifier in a RF module. The heat source dissipates up to $140 \mathrm{~W}$ (with heat flux $\sim 350 \mathrm{~W} / \mathrm{cm}^{2}$ ). Pressure drop and velocity fields are simulated in a commercial software ANSYS FLUENT. The package dimensions are shown in Fig. 5 with the heating and cooling regions indicated. Both liquid and vapor phase are simulated at steady-state and treated as laminar flows at the given maximal heat load. Since liquid is flowing in the porous wick structure, the vapor entrainment will only occur at an ultra-high relative speed, such as at low operating temperature and high heat load. This case rarely occurs in common heat pipe systems. Thus, in our simplified simulation, the vapor and liquid flows are separately considered. For the vapor phase flow, simulation domain is $65 \mathrm{~mm} \times 45 \mathrm{~mm} \times 0.35 \mathrm{~mm}$, after removing the solid package volume and wick structures of SVC. In contrast, the domain of the liquid phase simulation is limited to a hollow wick volume of $65 \mathrm{~mm} \times 45 \mathrm{~mm} \times 0.6 \mathrm{~mm}$. Simulation of the complex phase-change is avoided since only pressure and velocity are required in designing the SVC. Thus, the heating area is treated as an inlet with a constant mass flux of $6.08 \times 10^{-5} \mathrm{~kg} / \mathrm{s}$, converted from the input heat flux. The entire backside of the SVC on the condenser region is set as an exit with ambient pressure given. The model mesh size for vapor flow simulation and liquid flow simulation is 276,000 cells and 307,000 cells, respectively, with mesh resolution ensured to capture the flow behavior.

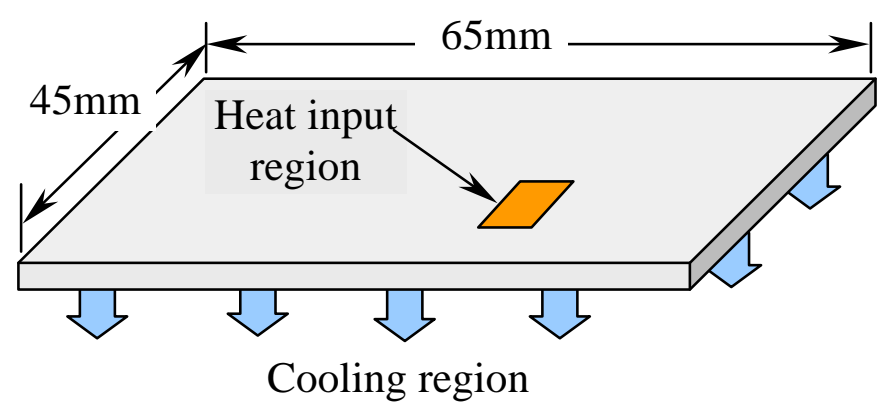


Fig. 5 Schematic diagram of simulation model

Figure 6 shows a contour plot of gauge pressure at the central cross-section of vapor flow channel. At the maximum heat load of $140 \mathrm{~W}$, the total pressure drop is as low as $75 \mathrm{~Pa}$ for the vapor phase flow. Because of the 2D spreading, the further the location is from the heating area, the higher the pressure difference of the vapor flow. The major pressure drop/gradient occurs close to the heating area where the converging vapor flow gains high flow velocity, creating the major flow friction. Figure 7 shows the corresponding velocity contour inside the SVC. The maximum vapor speed reaches $12.3 \mathrm{~m} / \mathrm{s}$. High pressure drop rate and high vapor flow rate occur at the same region close to the heating area.

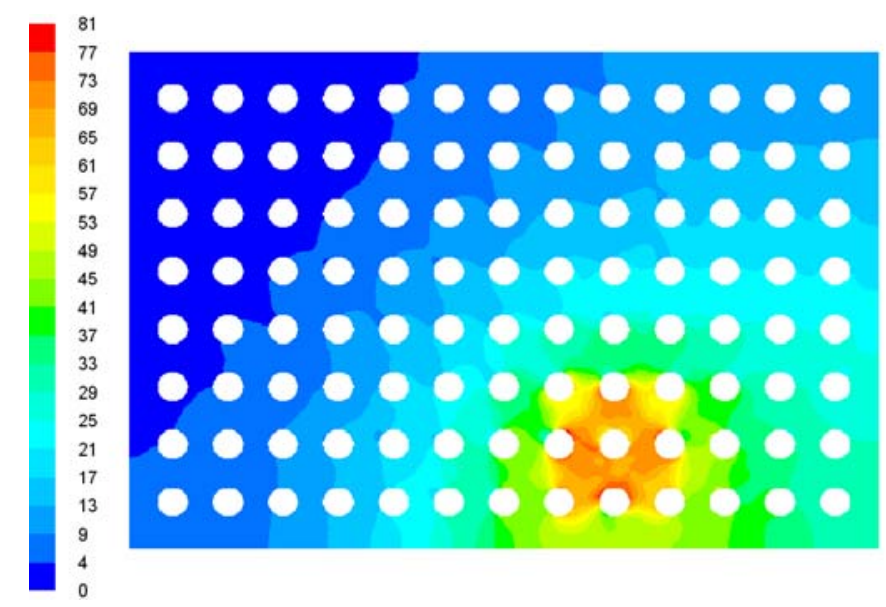

Fig. 6 Gauge pressure contour $(\mathrm{Pa})$ at central cross-section of vapor flow channel

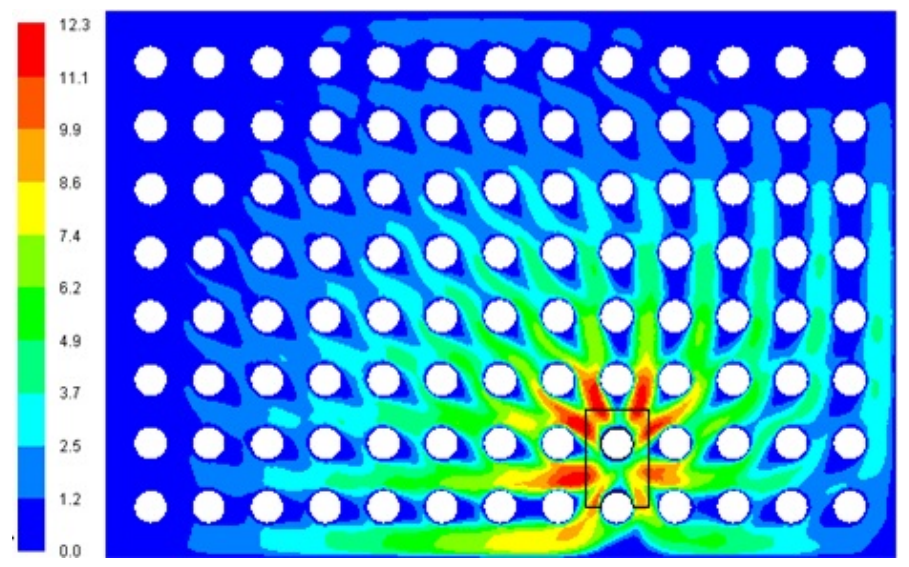

Fig. 7 Velocity contour $(\mathrm{m} / \mathrm{s})$ at central cross-section of vapor flow channel 
The liquid flow through porous wick structures is simulated by given a structural permeability of $10^{-11} \mathrm{~m}^{2}$. The permeability number is an average value of wick structures with particle diameter of 50-100 $\mu \mathrm{m}$. Gauge pressure contour of the liquid phase flow is plotted in Fig. 8. With the same mass flow rate, the maximum pressure drop reaches 3,055Pa, two orders of magnitude higher than the vapor flow. Similar to the vapor phase flow, the liquid flow in the wick structure has high velocity and pressure gradients near the heating area.

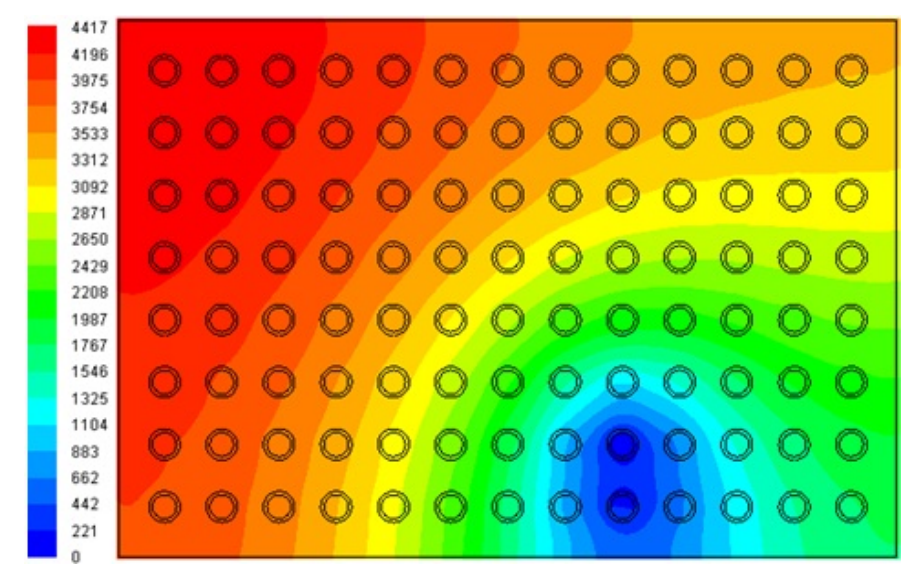

Fig. 8 Gauge pressure contour $(\mathrm{Pa})$ of the liquid phase flow at the middle of the wick structure

A close-up view of velocity pathlines of the liquid flow is shown in Fig. 9. The 3D flow pathlines show that liquid is supplied to the heating area from both the top wick and the bottom wick structure. Perpendicular wick structures on the supporting pillars provide bridges for liquid flow between the top and bottom wicks. The liquid flow speed reaches its maximum of $0.01 \mathrm{~m} / \mathrm{s}$ at the edge of the heating area where evaporation \& boiling starts and the liquid mass flow rate starts to reduce. 


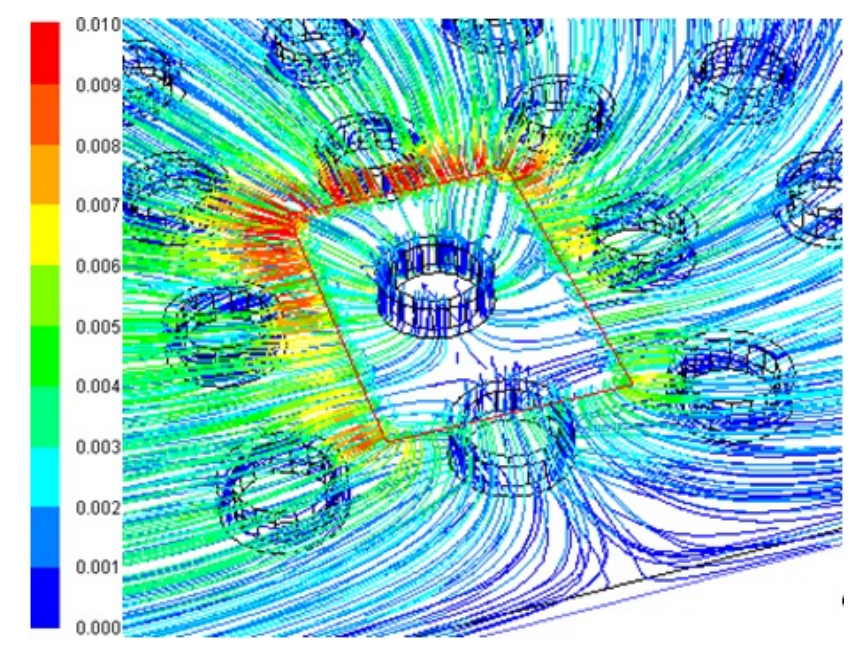

Fig. 9 Velocity pathlines $(\mathrm{m} / \mathrm{s})$ of the liquid phase flow near the heating area

\section{PRESSURE EQUILIBRIUM AND WICK STRUCTURE DESIGN}

Heat and mass transfer limits in traditional heat pipe theory must be taken into account when implementing the above 3D flow simulation results in the system. For various limits in the heat pipe theory, the viscous and sonic limits generally occur at low operating temperature due to a high liquid viscosity and a low vapor sonic speed in a confined flow space. Because SVC is typically applied between the electronic devices and heat sink, operating temperature falls into a range from 50 to $120^{\circ} \mathrm{C}$. High operating temperature reduces liquid viscosity and increases sonic speed. Thus, both sonic and viscous limits less likely occur in SVC if using water as operating fluid. On the other hand, boiling limit occurs due to vapor entrapped in the wick structure, blocking liquid return. However, the thin wick structure in the current SVC design can rapidly vent vapor without causing a vapor blanket. As a result, dynamic equilibrium in SVC is established under capillary limit, referring to that the driving capillary pressure is greater than or equal to the sum of pressure losses along the vapor/liquid path. By neglecting the pressure drop due to the evaporation and condensation at the liquid/vapor interface, the general expression of the capillary limit is: 


$$
P_{\text {cap }}=\frac{2 \sigma}{r_{e f f}} \geq \Delta p_{l}+\Delta p_{v}+\rho_{l} a L \sin \phi
$$

Here, $\sigma$ is the surface tension, $r_{\text {eff }}$ is effective radius of the wick structure, $\rho_{l}$ is the liquid density, $L$ is the maximum length of the SVC, $a$ is the acceleration, and $\phi$ is the SVC inclined angle to the gravitational force ( $90^{\circ}$ for the worst case). $\Delta P_{l}$ and $\Delta P_{v}$ are pressure drops of the liquid and vapor phase flows from the simulations. The hydrostatic pressure, $\rho_{l} a L \sin \phi$, may significantly reduce the wick pump capability in high g environment. Therefore, wick structure design must consider the corresponding centrifugal force requirements of its applications.

By implementing numerical modeling results of $\Delta P_{l}$ and $\Delta P_{v}$ in Eq. (1), different pressure drops versus the wick pore size (equal to half of the particle diameter), as well as hydrostatic pressure, are given in Table 1. Although the SVC is able to achieve $350 \mathrm{~W} / \mathrm{cm}^{2}$ cooling under $3 \mathrm{~g}$ centrifugal force, more than 25 percent driving pressure is used to overcome the g effect. While further increasing the gravitational force to $10 \mathrm{~g}$, to accommodate the high hydrostatic pressure drop and high viscous loss in liquid phase, heat flux and wick pore size must be reduced to $35 \mathrm{~W} / \mathrm{cm}^{2}$ and $5 \mu \mathrm{m}$, respectively.

Table 1 Pressure loss in different wick structure under g forces

\begin{tabular}{|c|c|c|c|c|c|}
\hline$q_{\max }, \mathrm{W} / \mathrm{cm}^{2}$ & Wick design for g load & $P_{c a p}, \mathrm{kPa}$ & $\Delta P_{l}, \mathrm{kPa}$ & $\Delta P_{v}, \mathrm{kPa}$ & $\rho_{l} a L, \mathrm{kPa}$ \\
\hline 350 & $r_{\text {eff }}=50 \mu \mathrm{m}$ at $3 \mathrm{~g}$ & 4.5 & 3.06 & 0.053 & 1.2 \\
\hline 35 & $r_{e f f}=5 \mu \mathrm{m}$ at $10 \mathrm{~g}$ & 45.0 & 30.6 & 0.058 & 4.5 \\
\hline
\end{tabular}

To enable heat transfer operation of the SVC in high g environments (up to 10g), multiscale wick structures in the SVC are designed to provide two parallel liquid supply paths from the condensation region to the evaporator. As shown in Table 1, the fine wick structure is composed 
of silicon pillars $10 \mu \mathrm{m}$ in diameter and pillar gaps $5 \mu \mathrm{m}$ in width. It has high capillary force to overcome high gravitational force up to $10 \mathrm{~g}$, but is only capable of a limited mass supply due to the high viscous loss. In contrast, the coarse wick structure path is composed of large silicon pillars $100 \mu \mathrm{m}$ in diameter and pillar gaps $50 \mu \mathrm{m}$ in width. It enables high flow transport rate but is limited by gravitational force up to 3g. The multiscale wick structures accommodate the requirements of both high heat flux heat transfer and operation in high g environment.

\section{DEVELOPMENT OF WICK STRUCTURES AND SVC}

Development of SVC with the multiscale wick structures is based on MEMS microfabrication technique. This approach allows precise definition on the wick pillar sizes and distribution, enabling optimization of the liquid and vapor flows and maximization of the heat transfer capability.

\section{WICK STRUCTURE FABRICATION}

Besides the fine and coarse wick structures, perpendicular groove wick with gap width of $100 \mu \mathrm{m}$, is made on the sidewall of the supporting pillars to provide the vertical liquid transport between the top and bottom wicks of SVC. Thus, wick structures with three different cavity sizes from $5 \mu \mathrm{m}$ to $100 \mu \mathrm{m}$ but an identical depth of $150 \mu \mathrm{m}$ must be fabricated on a same wafer. The fabrication challenge is overcome by introducing a dual mask set, including a patterning mask and an oxide mark, to realize the difference in wick structures. Before a patterning mask is applied to etch the wick structures, an oxide mask is used on the coarse wick area/large wick cavity area to delay the etching speed of the large gaps. By balancing the etch speeds between the coarse and fine wick structures, etching height difference is minimized to a few micrometers. As shown in Fig. 10a, three different wick structures co-exist at an area close to the evaporator. 
The fine wick is composed of micro pillars $10 \mu \mathrm{m}$ in diameter and cavities $100 \mu \mathrm{m}$ in diameter for vapor ventilation. The perpendicular groove wick is embedded between the fine and coarse wicks, providing a shortcut path for liquid supply. A separation line between the coarse and fine wicks is illustrated in Fig. 10b. Both the wicks go through the heating area, covering both capabilities for high heat flux cooling and anti-gravitational force.
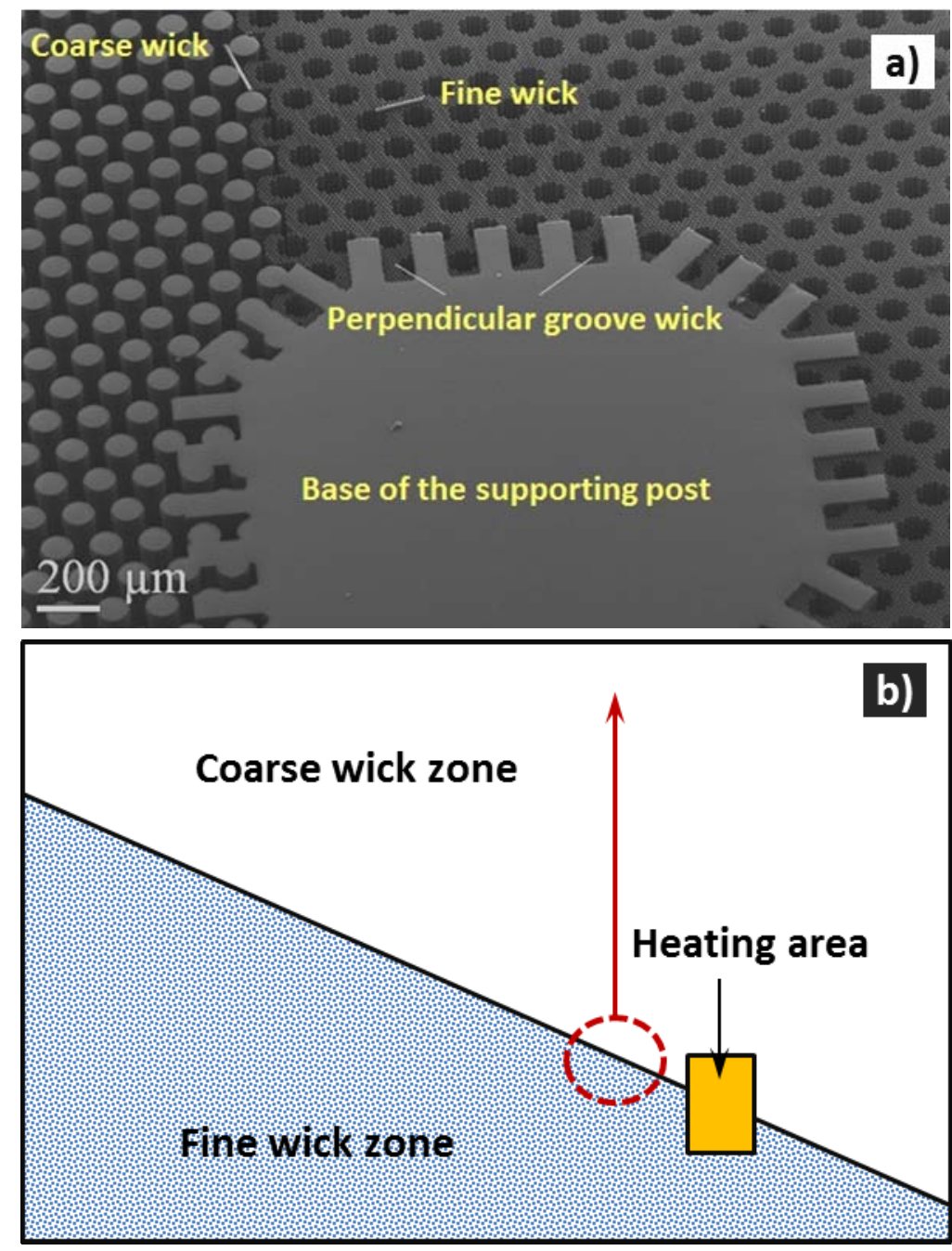

Fig. 10 Multiscale wick structures etched on the SVC top wafer

The bottom wafer only contains the coarse wick structure with cubic pillars $200 \mu \mathrm{m}$ in width and $100 \mu \mathrm{m}$ gaps. Since the liquid flow speed is much lower in the condensation region, the wick 
thickness/pillar height is reduced to $100 \mu \mathrm{m}$. The standard lithographic patterning and deep etch are applied to form the coarse wick structure on the bottom wafer.

\section{VAPOR CHAMBER FABRICATION}

In early development, SVC is made from two silicon wafers, the top and bottom wafers. After etching vapor flow channel and wick structures, these two wafers are bonded with each other to form a vapor chamber. However, this approach faces fabrication challenges when making a SVC $\geq 1 \mathrm{~mm}$. For example, if using two $500 \mu \mathrm{m}$ thick wafers to fabricate $1 \mathrm{~mm}$ thick SVC, the total etch depth reaches $300 \mu \mathrm{m}$, including the wick structures and the vapor flow cavity. The deep silicon etch, as well as difference in etching depth, can cause instability of the thick photoresist layer and project serious risks on the final yield. Thus, a triple stack process is introduced to achieve reliable MEMS fabrication of SVC.

As illustrated in Fig. 11, the 1mm thick SVC is made from three silicon wafers. From the top

to the bottom, the wafer thicknesses are $350 \mu \mathrm{m}, 350 \mu \mathrm{m}$ and $300 \mu \mathrm{m}$, respectively. With completion of wick etching on the top and bottom wafers, a half way trenches $(\sim 200 \mu$ m deep) around the vapor flow cavities are etched on the $350 \mu \mathrm{m}$ thick center wafer. After glass-frit bonding the center wafer with the top wafer, the second etch is performed on the backside of the two stacked wafers to etch through the trenches completely. The vapor flow cavities are formed by removing drop-off parts, as shown as vapor chamber cavity in Fig. 11. The last assembly step is to apply another glass-frit bond to bond the bottom wafer with the wafer stack, forming a closed vapor chamber. Liquid charging ports $1 \mathrm{~mm}$ in diameter are pre-etched on the backside of the bottom wafer. The bonded wafers are diced into $50 \mathrm{~mm} \times 70 \mathrm{~mm}$ SVC after an e-beam evaporation process to deposit $1.5 \mu \mathrm{m}$ thick Au on the top surface. More detailed MEMS process can be found in the research paper of Cai, et al. ${ }^{[12]}$. 


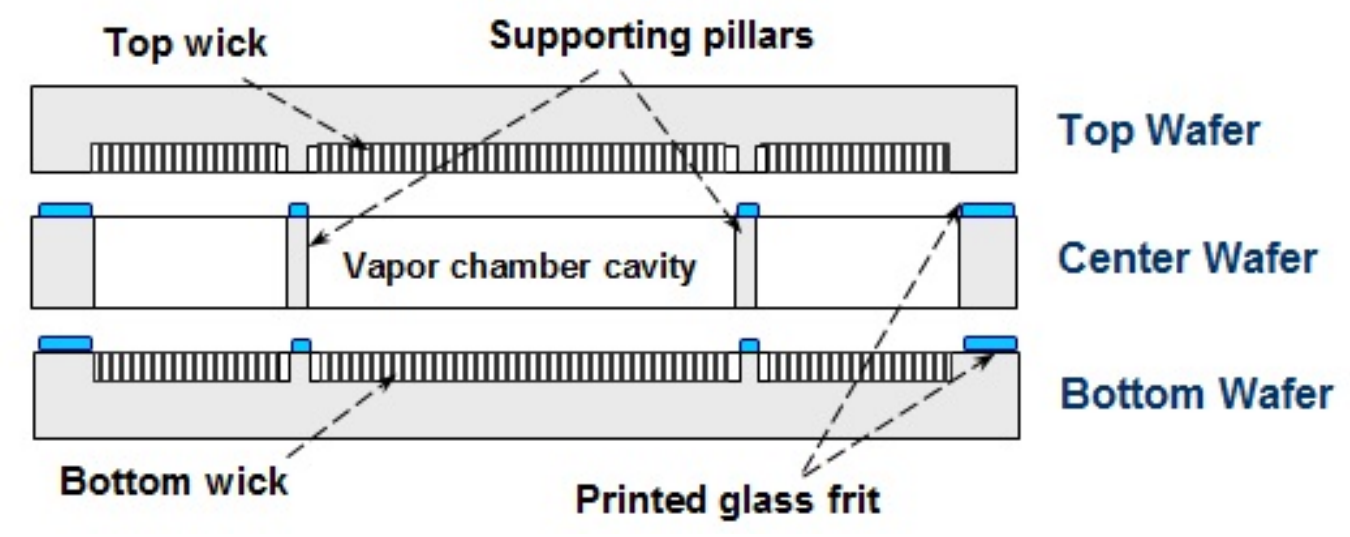

Fig. 11 SVC MEMS assembly

Figure 12 shows the assembled 1mm thick SVC and SEM image of its cross section. In a destructive test shown in Fig. 12a, the SVC is broken by air pressure of 2.0atm, meeting the development goal for withstanding the saturation pressure at $120^{\circ} \mathrm{C}$ ambient. However, compared with the given pressure of $1 \mathrm{MPa}$ in the structural modeling, the maximum yield strength is significantly lower. The reason caused this low strength may attribute to material impurity, stress concentration at the sharp corners between two bonded wafers, or glass-frit bond failures on the supporting posts. Thus, further structural improvement of the SVC might be needed for high temperature thermal management. A local cross section of the SVC, shown in Fig. 12b, contains the fine wick structure on the top cover, a perpendicular support pillar with vertical groove wick, and the coarse wick structure on the bottom cover. A continuous liquid supply path from the condensation region (on the bottom cover) to the evaporator area (the fine wick on the top cover) is built through the middle groove wick. 


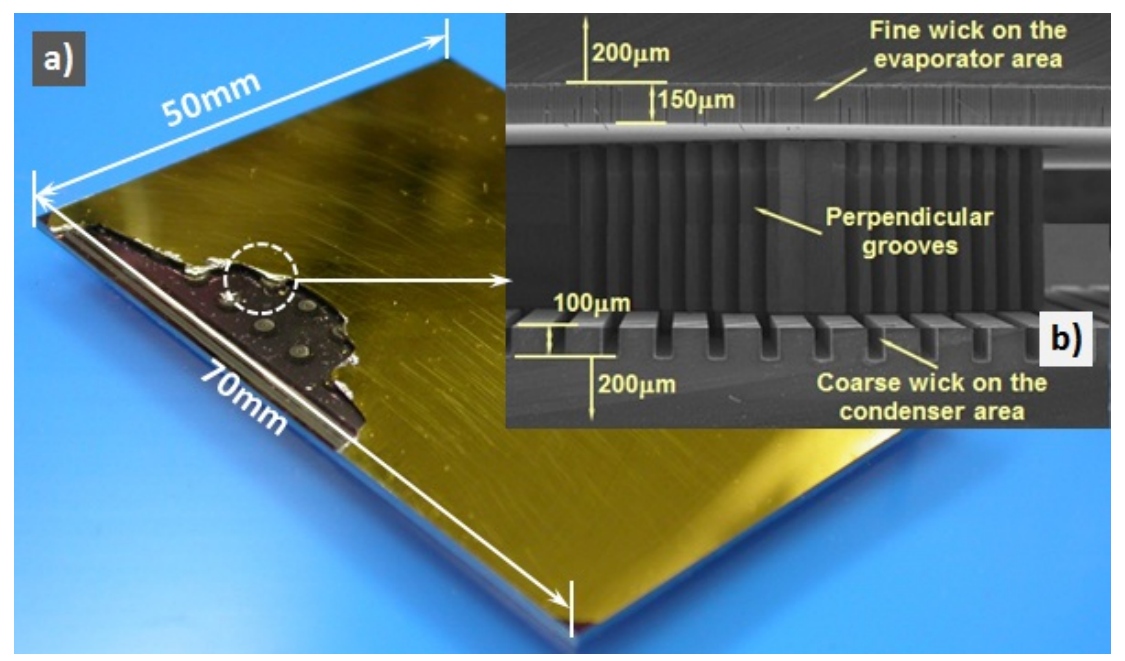

Fig. 12 Ultrathin and large scale SVC: a) supporting pillars and bonding edge are exposed after a SVC destructive test, b) the cross-section view of the 1mm thick SVC

After all MEMS processes, the SVC coming out of the cleanroom must be evacuated, followed by charging approximately $0.45 \mathrm{cc}$ distilled water to saturate the wick structure. To reach the best heat transfer performance, iteration of the evacuation and charging processes might be needed. After finishing this process, the last step is to crimp and solder-seal the charging tube.

\section{HEAT TRANSFER CHARACTERIZATION}

Heat transfer characterization is based on measuring the effective thermal conductivity of the SVC. Both 1D and 2D heat transfer modes are implemented for this characterization.

\section{ID EFFECTIVE THERMAL CONDUCTIVITY MEASUREMENT}

Experimental setup of the 1D heat transfer characterization is shown in Fig. 13. The SVC is horizontally set on a G10 supporting frame. Three ceramic heaters $(16 \mathrm{~mm} \times 7 \mathrm{~mm})$ are mounted in series to heat the evaporator end. A liquid-cooled copper cold plate ( $7 \mathrm{~mm}$ in width) is applied on the condenser end for cooling. Heat transfer distance between the center of the heating area and 
the center of the cooling area is $60 \mathrm{~mm}$, approximately. The evaporator temperatures are measured by two E-type thermocouples, attached to the SVC under the ceramic heaters. Another two thermocouples are embedded between the SVC and the copper cold plate to monitor the condenser temperatures. Measurement errors from all the E-type thermocouples are less than $0.1^{\circ} \mathrm{C}$ within the designed operation temperature range. To reduce heat loss, both the top and the bottom surfaces of the SVC are thermally insulated by ceramic fabrics. After thermal insulation, heat loss is less than 2 percent in the test temperature. Experiments are conducted at room temperature of $22+/-0.5^{\circ} \mathrm{C}$. Input power is about $3 \mathrm{~W}$. The coolant temperature flowing through the copper cold plate is controlled at $50+/-0.5^{\circ} \mathrm{C}$, setting the SVC condenser temperature at $51^{\circ} \mathrm{C}$, approximately. All temperature data are recorded through a data-acquisition of Agilent 349710A and processed by a computer.

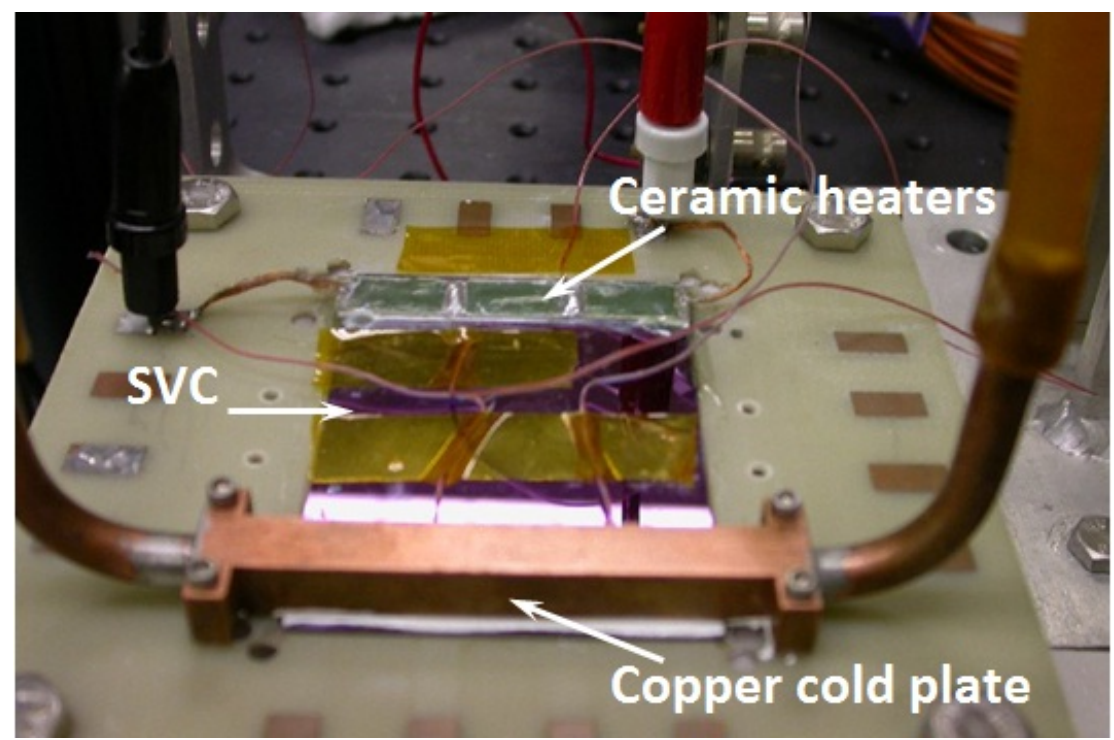

Fig. 13 1D measurement setup of the SVC effective thermal conductivity

Based on the temperature measurement data, temperature differences between the evaporator and condenser sections, $\Delta T$, are averaged and substituted into the Fourier's law. The effective thermal conductivity, $k_{\text {eff }}$, is written as 


$$
k_{\text {eff }}=\frac{Q}{A_{c} \cdot \Delta T} t
$$

Here, $A_{c}$ is the cross section area $(50 \mathrm{~mm} \times 1 \mathrm{~mm})$ along heat transfer direction, $Q$ is input heat, and $t$ is the distance between the centers of the evaporator and condenser. Like conduction in solid materials, the effective thermal conductivity represents the phase change heat transfer effectiveness through the SVC. A steady state heat transfer is demonstrated and shown in Fig. 14. During the recording period of the first 25 minutes, the effective thermal conductivity of the SVC remains steady. No performance degradation is observed when extending the experimental time to 5 hours. The average effective thermal conductivity reaches $\sim 11,000 \mathrm{~W} / \mathrm{m}$.K. It is slightly above the development goal of $10,000 \mathrm{~W} / \mathrm{m} . \mathrm{K}$ indicated by the dash line. Both the high effective thermal conductivity and the steady state operation indicate that the SVC is a well evacuated and hermetically sealed system without micro leakage or generation of non-condensable gas from chemical reactions. In the temperature difference domain, the high effective thermal conductivity reflects a small temperature drop less than $0.5^{\circ} \mathrm{C}$ between the SVC evaporator and the condenser. With $0.1^{\circ} \mathrm{C}$ measurement error of the Agilent $349710 \mathrm{~A}$, the effective thermal conductivity shows fluctuations between 10,000 to $12,000 \mathrm{~W} / \mathrm{m} . \mathrm{K}$. 


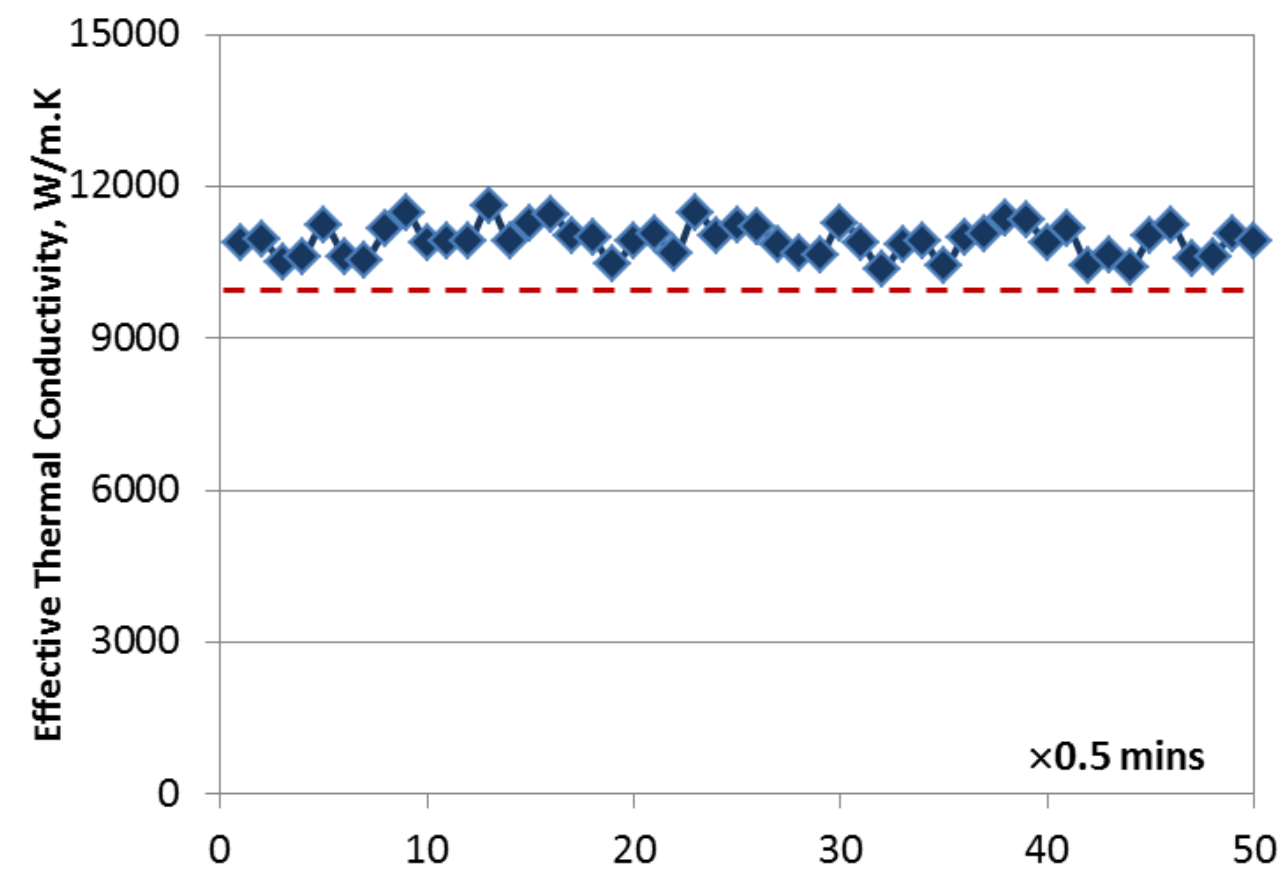

Fig. 14 SVC effective thermal conductivity versus time

\section{D EFFECTIVE THERMAL CONDUCTIVITY MEASUREMENT}

Characterization of the 2D effective thermal conductivity employs the concentrated heat source offset from the SVC center, as shown in Fig. 5. A ceramic heater $5 \mathrm{~mm} \times 8 \mathrm{~mm}$ in size, corresponding to the GaN power amplifier in the RF module, is solder-bonded on the evaporator side of the SVC. The melting point of the $\mathrm{Pb} / \mathrm{Sn}$ solder is $185^{\circ} \mathrm{C}$, approximately. Temperature drop across the solder interfacial layer is negligible at the test heat flux range. An aluminum heat sink, covering the entire upper surface, is epoxy-attached to the SVC condenser, as shown in Fig. 15. A 12-volt power supply is used to drive a fan for cooling the heat sink. Four E-type thermocouples are used to measure temperatures from the hottest heating area to the coldest/furthest corner (upper-left corner in Fig. 5) of SVC, with equal distance intervals. After all power and measurement wires are connected, the bottom surface is insulated with porous ceramic material. Experiments are conducted at the same ambient conditions as the 1D 
characterization. The driving voltage of the fan is precisely controlled so that temperature at the furthest corner of the SVC is at approximate $50^{\circ} \mathrm{C}$. Because of the local heat flux reaches the minimal at the furthest corner, temperature at this point is closer to the inner vapor temperature. Thus, this corner temperature is defined as the operating temperature of SVC. The maximum heat flux added to the SVC is limited below $160 \mathrm{~W} / \mathrm{cm}^{2}$. Beyond this heat flux, $\mathrm{Pb} / \mathrm{Sn}$ solder, also bonding the power leads to the ceramic heater electrodes, approaches to its melting point and breaks the electrical circuit.

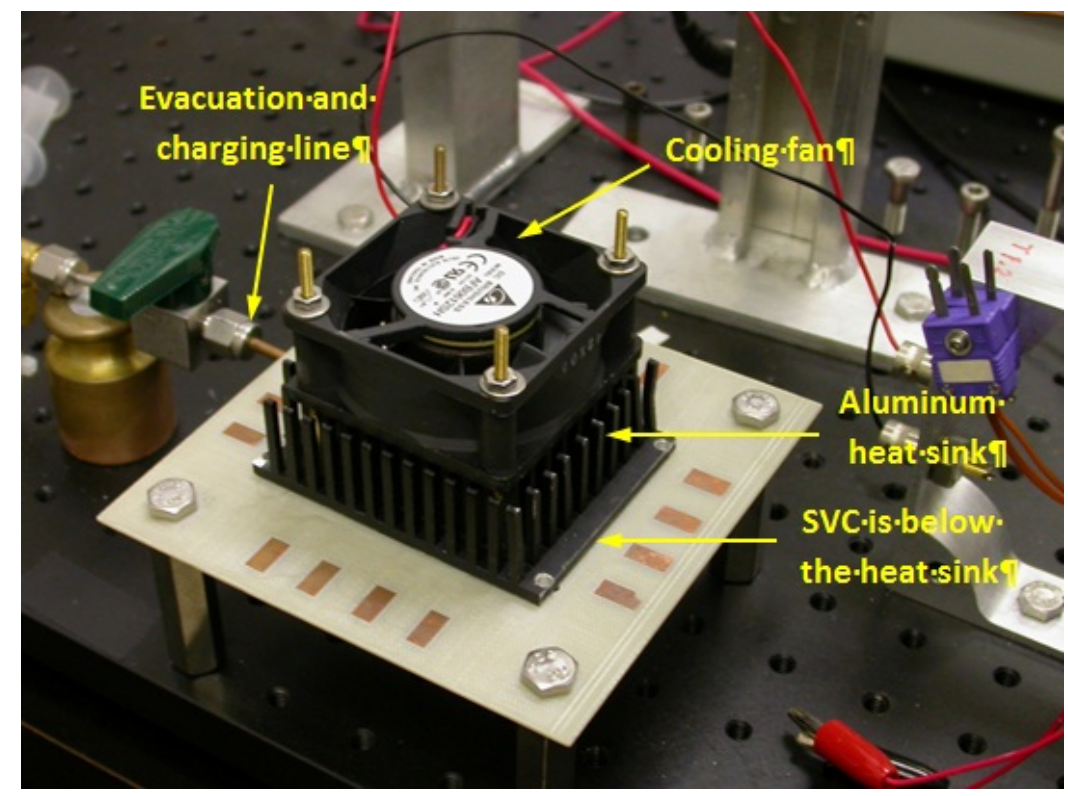

Fig. 15 2D measurement setup of the SVC effective thermal conductivity

Characterization of the effective thermal conductivity combines both the efforts in the experimental measurement and numerical modeling. With an input heat load of $60 \mathrm{~W}$, the characterization is started with measuring temperature distribution on a $1 \mathrm{~mm}$ thick copper plate. Based on the experimental setup, conduction-convection modeling is also applied. A heat transfer coefficient is specified on the upper surface of the copper plate to account for convection. The SVC bottom surface is treated as adiabatic. By matching numerical temperature distribution to the experimental data, the heat transfer coefficient of the fan cooling is obtained. The copper 
plate with well-known thermal conductivity is used to precisely calibrate the heat transfer coefficient of the convection cooling in experiments. At the same convection cooling conditions, temperature distribution of the SVC is measured thereafter. By implementing the calibrated convection heat transfer coefficient and specifying an effective thermal conductivity in the numerical model (assuming the SVC as a solid material), a temperature distribution can be obtained. The SVC effective thermal conductivity is determined when the minimal root-meansquare error between the numerical result and the experimental measurement data is reached.

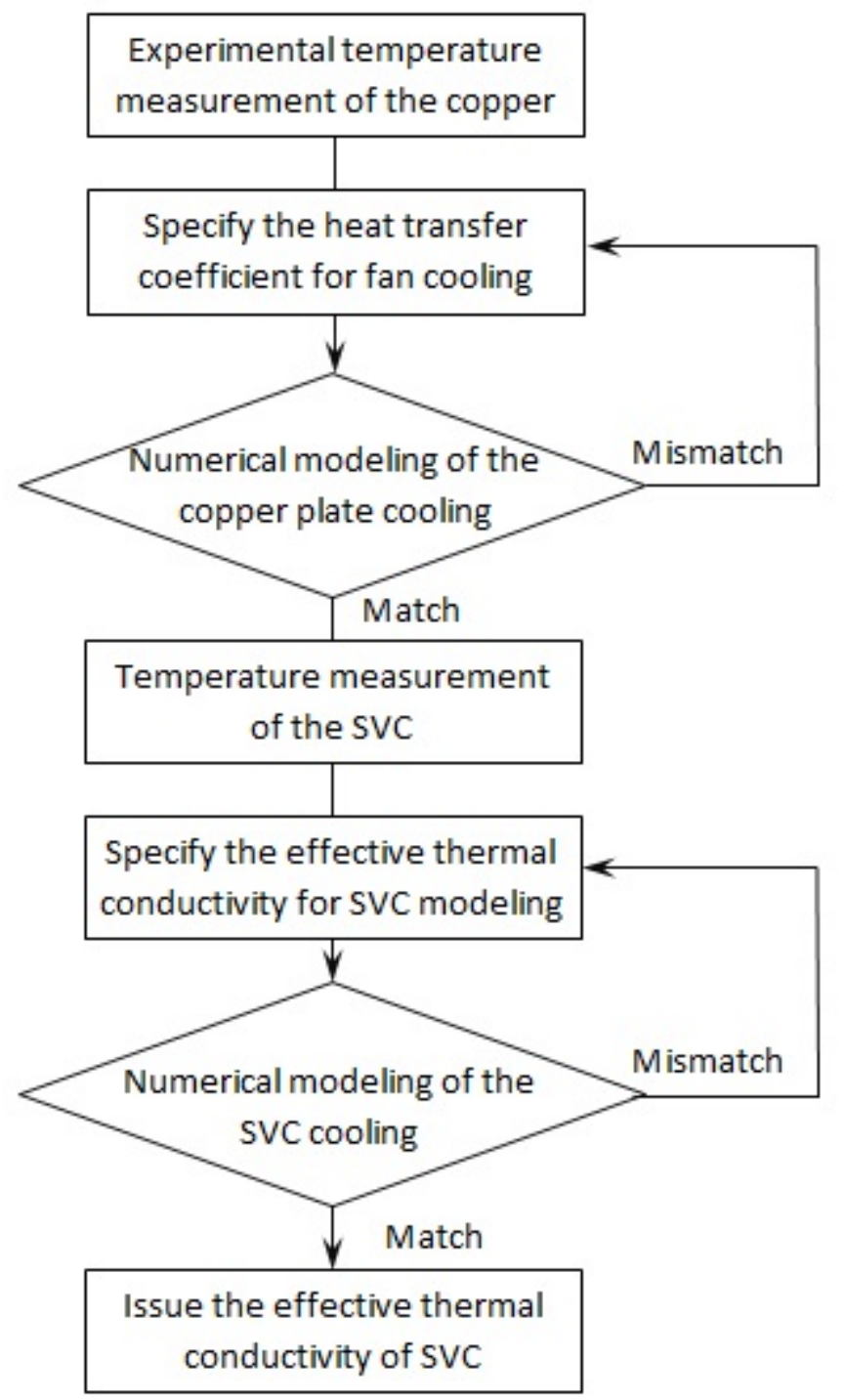

Fig. 16 Characterization of the effective thermal conductivity of SVC 
Experimental results, in the form of the maximum temperature difference versus input heat flux, are given in Fig. 17. The copper plate temperature linearly increases versus input heat flux. At heat flux of $60 \mathrm{~W} / \mathrm{cm}^{2}$, the maximum temperature difference across the entire surface is $28^{\circ} \mathrm{C}$. At heat flux of $150 \mathrm{~W} / \mathrm{cm}^{2}$, it reaches $74^{\circ} \mathrm{C}$. In contrast, the maximum temperature difference of the SVC is less than $5^{\circ} \mathrm{C}$ with input heat flux of $150 \mathrm{~W} / \mathrm{cm}^{2}$.

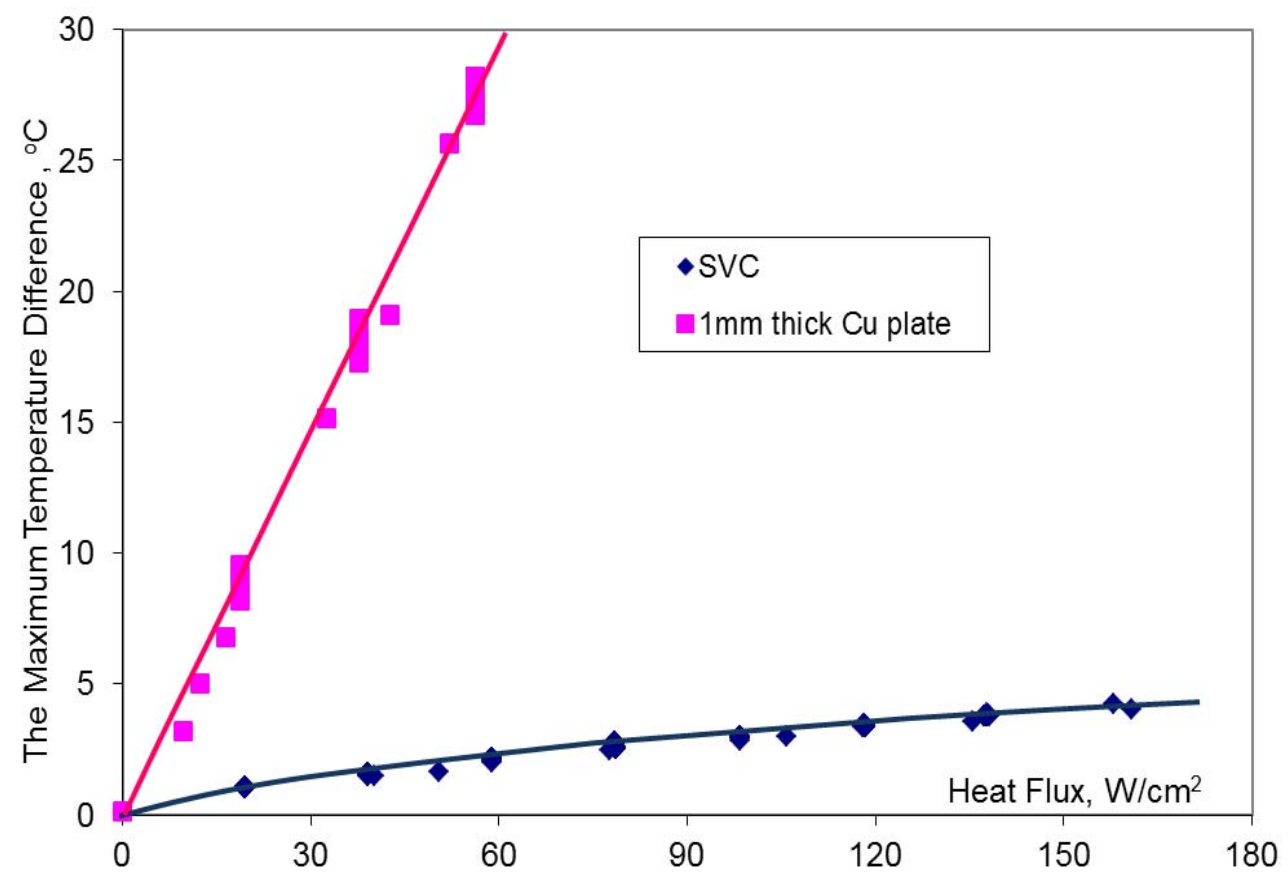

Fig. 17 SVC significantly reduces the maximum temperature difference, compared with the copper plate.

At input heat flux of $150 \mathrm{~W} / \mathrm{cm}^{2}$, simulation results for $1 \mathrm{~mm}$ thick copper plate and SVC, in the form of temperature contours, are shown in Fig. 18. A significant difference can be seen between heat transfer in copper plate and in SVC. Using the temperature distribution data obtained from experiments, as well as through the characterization approach illustrated in Fig. 16, the effective thermal conductivity of the SVC reaches $11,500 \mathrm{~W} / \mathrm{m} . \mathrm{K}$. 

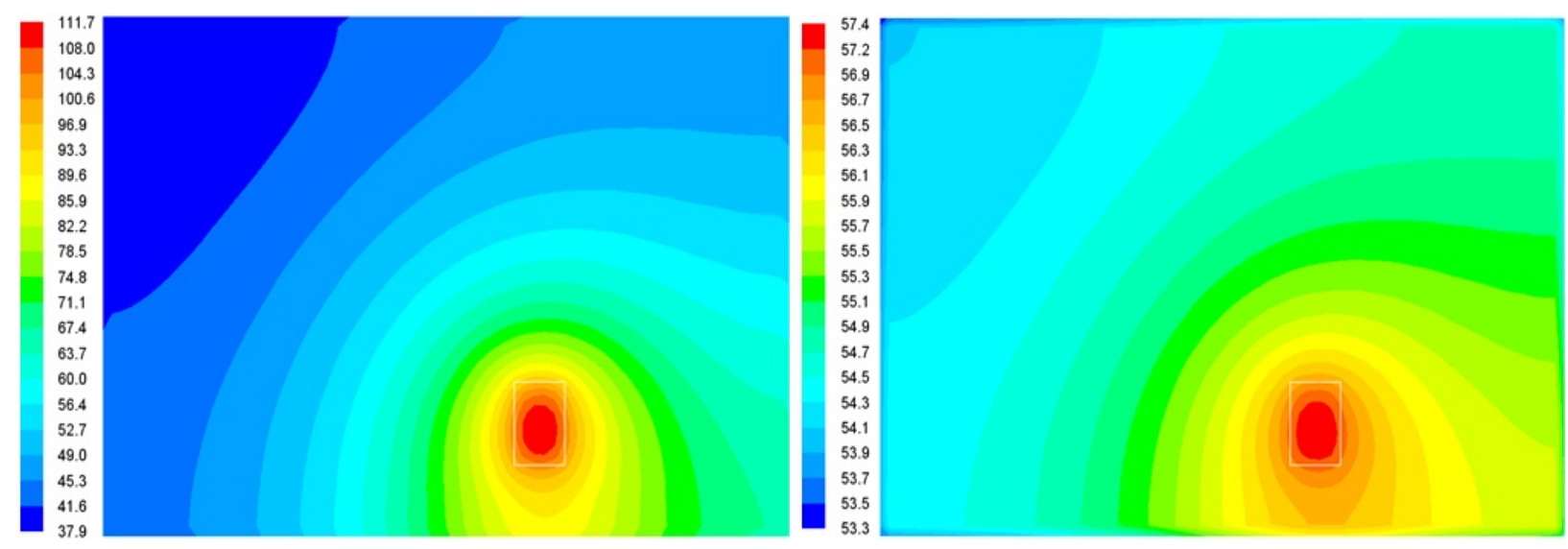

Fig. 18 Temperature courtours with input heat flux of $150 \mathrm{~W} / \mathrm{cm}^{2}$ : a) $1 \mathrm{~mm}$ copper plate, b) SVC

Demonstration of anti-g operation of the SVC must be conducted on a centrifugal test bed with a capability to conduct precise dynamic temperature measurement. The future efforts will focus on highly efficient heat transfer demonstration of the SVC under high gravitational forces.

\section{CONCLUSIONS}

Development of the silicon based vapor chamber (SVC) covers the efforts in multiple aspects, including structural safety, quantification of heat and mass transports, MEMS microfabrication, and heat transfer characterization. The following conclusions are drawn from the comprehensive development efforts:

1. Successful development leads to emergence of the large scale and ultrathin heat transfer devices with the dimension of $50 \mathrm{~mm} \times 70 \mathrm{~mm} \times 1 \mathrm{~mm}$. The compact and lightweight SVC is able to be directly integrated with complex 3D electronic systems without introducing thermal interface and thermal expansion mismatch, providing a benign thermomechanical solution for modern electronics. 
2. Passive phase change and mass circulation inside SVC enable highly efficient heat transfer/spreading. For both the 1D and 2D heat transfer models, the effective thermal conductivity of SVC reaches $\sim 10,000 \mathrm{~W} / \mathrm{m}$.K, over 20 times higher than copper.

\section{ACKNOWLEDGEMENTS}

This research is sponsored by DARPA/MTO under contract No. N66001-08-C-2009 and Teledyne IR\&D Program. The views, opinions, and/or findings contained in this article/presentation are those of the author/presenter and should not be interpreted as representing the official views or policies, either expressed or implied, of the Defense Advanced Research Projects Agency or the Department of Defense. The authors would like to thank Dr. Avram BarCohen and Dr. Berinder Brar for their support in this study.

\section{Reference:}

[1] A. Faghri, Heat Pipe Science and Technology, Taylor and Francis, 1995.

[2] G. P. Peterson, A. B. Duncan, M. H. Weichold, Experimental Investigation of Micro Heat Pipes Fabricated in Silicon Wafers, Journal of Heat Transfer, Vol. 115, pp751-756, 1993.

[3] M. Ivanova, C. Schaeffer, Y. Avenas, A. Laï, C. Gillot, Realization and thermal analysis of silicon thermal spreaders used in power electronics cooling, IEEE ICTC, Maribor, Slovenia, 2003.

[4] C. Gillot, Y. Avenas, N. Cézac, G. Poupon, C. Schaeffer, E. Fournier, Silicon heat pipes used as thermal spreaders, IEEE Transactions on Components and Packaging Technologies, Vol.26, No 2, pp332-339, 2003. 
[5] M. Ivanova, A. Lai, C. Gillot, N. Sillon, C. Schaeffer, F. Lefèvre, M. Lallemand and E. Fournier, Design, Fabrication and Test of Silicon Heat Pipes with Radial Microcapillary Grooves, Itherm’06, 0-7803-9524-7, pp545-551, 2006.

[6] M. Hamdan, D. Cytrynowicz, P. Medis, A. Shuja, H. T. Henderson, E. Golliher, K. Mellott and C. Moore, Loop Heat pipe (LHP) Development by Utilizing Coherent Porous Silicon (CPS) Wicks, Itherm’02, 0-7803-7152-6, 2002.

[7] M. L. Berre, S. Launay, V. Sartre and M. Lallemand, Fabrication and Experimental Investigation of Silicon Micro Heat Pipes for Cooling Electronics, Journal of Micromechanics and Microengineering, Vol.13, pp436-441, 2003.

[8] S. Lips, J. Bonjour and F. Lefevre, Investigation of Evaporation and Condensation Processes Specific to Groove Flat Heat Pipes, Frontiers in Heat Pipes, 1, 023001, 2010.

[9] U. Vadakkan, G. M. Chrysler and S. Sane, Silicon/Water Vapor Chamber as Heat Spreaders for Microelectronic Packages, Semiconductor Thermal Measurement and Management Symposium, pp.182 - 186, 2005.

[10] Q. Cai, B. Chen, C. Tsai and C. L. Chen, Development of Scalable Silicon Heat Spreader for High Power Electronic Devices, Journal Thermal Science and Engineering Applications, Vol.1, Iss. 4, 2010.

[11] V. Lindroos, Ml Tilli, A. Lehto and T. Motooka, Handbook of Silicon Based MEMS Materials and Technologies, Elsevier, 2009, pp10.

[12] Q. Cai, B. Chen and C. Tsai, Development and Tests of High Performance Silicon Vapor Chamber, Journal of Micromechanics and Microengineering, Vol.22, 035009, 2012. 